\title{
Original Article \\ The Epidemiological and Clinical Characteristics of 2019 Novel Corona Virus Disease (COVID-19) in Balochistan, Pakistan
}

\author{
Qurat ul Ain*, Ehsan Ahmed Larik, Abid Saeed, Zubair Ahmed Khosa, Muhammad Arif, Ambreen \\ Chaudry, Tamkeen Ghafoor, Mirza Amir Baig
}

Field Epidemiology and Laboratory Training Program, National Institute of Health, Islamabad, Pakistan

*Corresponding Author: dr.quratulain90@gmail.com

Received: 5-9-2020

Revised: 1-10-2020

Published: 5-10-2020

Keywords:

COVID-19,

Epidemiology,

Prevalence,

Balochistan.

\begin{abstract}
Background: The unprecedented outbreak of 2019 novel coronavirus disease (COVID-19) drastically spread worldwide. The study was aimed to articulate the findings of a descriptive and clinical characteristic, also to access the potential risk factors link with the spread of COVID-19. Method: The COVID-19 cases reported through April 30, 2020, were extracted from Balochistan's COVID-19 Electronic Dashboard. All cases from March to April 2020 were included. The results of the laboratory finding as well as data acquired through COVID-19 Dashboard were cleaned; descriptive exploratory analysis and chi-square were calculated to demonstrate the association using Epi- Info. Results: A total of 1381 patient records extracted and screened. Of these, 1218 suspected cases and 1049 confirmed cases contributed to the analysis. Among confirmed cases, $77 \%$ (811) were male. The most affected age group was $60-69$ years (attack rate 1.90/10,000), mean age was $36 \pm 17.11$ SD with age range 2 months-94 years. District Quetta 82\% (864) and district Pishin 5\% (55) remained the epi-center for high attack rates. Among confirmed cases, a total of 14 deaths occurred for an overall Case fatality rate of $1.33 \%$. The epi surge was peaked around March 19, April 5, and April 24, 2020. Among high-risk personals, those who had contact with infected individuals' showed a high association of 97\% (323/333) than without any contact $87 \%(221 / 254)$. Those who had travel history showed a prevalence of $86 \%$ $(87 / 101)$ than in those who did not $59 \%(60 / 104)$ while those admitted in hospital with comorbid conditions showed a prevalence of $70 \%(26 / 37)$ than in those who did not $13 \%$ (6/46). Conclusion: COVID-19 epidemic has spread rapidly in the province. A series of multidimensional public health interventions, a cost-effective surveillance system, and the adoption of safe working practice, awareness sessions are necessary to control the COVID-19 outbreak.
\end{abstract}

Cite this article as: Qurat ul Ain., Larik, E.H., Saeed, A., Khosa, Z.A., Arif, M., Chaudry, A., Ghafoor, T., Baig M.A. (2020). The Epidemiological and Clinical Characteristics of 2019 Novel Corona Virus Disease (COVID-19) in Balochistan, Pakistan. Journal of basic and applied Research in Biomedicine, 6(2): 98-105

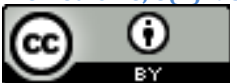

the work in the manner specified by the author or licensor.

\section{INTRODUCTION}

Severe acute respiratory syndrome coronavirus 2 (SAR-CoV-2) is a zoonosis caused by an enveloped RNA virus of family Coronaviridae, Coronaviruses are exclusively distributed in humans and other mammals as well. Though majority human coronavirus infections are mild, the severe acute respiratory syndrome coronavirus (SARS-CoV) and Middle East respiratory syndrome coronavirus (MERS-CoV) epidemics have caused more than 10,000 cumulative cases in the past two decades (Bastola, 2020). That infects the respiratory, gastrointestinal, hepatic, and central nervous systems of humans as well as domestic and wild animals The newly discovered severe acute respiratory syndrome coronavirus 2 (SAR-CoV-2) was identified to be responsible for creating an alarm across the globe by the end of December 2019. The current ongoing Covid-19 outbreak has emerged in China, Wuhan, and the epidemic then extended to all other parts of the country, but also to boarding countries including Russia, Nepal, and other closely connected regions (Bastola, 2020; Huang, 2020). The source of COVID-19 is yet unknown, however, initials findings show the close similarity of the virus with other coronaviruses. It has been hypothesized that bats are the most probable source of transmission and cases were linked to Wuhan's seafood market (Lee, 2020). However, it has been presumed that the virus can enter into a human through an intermediate animal host while human-to-human transmission has started by an airborne route. The ability of the virus to infect and replicate in other animals is yet unknown (Bogoch, 2020;Carlos, 2020; Lu, 2020).

More worryingly, On January 30, 2020, china confirmed 7734 cases and 90 other confirmed cases have been reported from a number of countries including United States, Canada, Australia, Germany, Japan, Malaysia, Thailand, and Taiwan with the case fatality rate of 2.2\% (Bassetti, 2020). The unprecedented epidemic situation was disturbing the health and economy of affected and 
all other countries. So far (as of January 30, 2020) SARS-CoV-2 has been declared as a public health emergency by the World Health Organization (WHO), has spread to more than 216 countries (Millán-Oñate, 2020; Yang, 2020; Zhu, 2020).

Global concern and increase in cumulative cases raised up the serious concerns for low and middleincome countries like Pakistan, where the health system tends to be weaker, lacking updated laboratory resources and surveillance tends to be rudimentary.

Since January 30, 2020, after public health emergency declared by WHO, Pakistan's health system has set an emergency committee to interrupt the spread of COVID-19 by early detection, screening, isolation, contact tracing, and prompt treatment. Pakistan being shared borders with China and Iran, a high influx of travel and trade, has been at high risk of viral transmission. The first two confirmed cases have been reported on 26 February and later on imported cases have been reported from other countries like United Kingdom, Saudi Arabia, and Italy. On March 9, 2020, the Department of Health Balochistan, COVID-19 emergency operational center was informed of the first suspected case infected with SARS-CoV-2 linked to travel history back from Iran. In the meantime, the cluster of cases was identified through porous border routes. Investigation and management of the epidemic were immediately initiated to identify further cases and contacts in the province.

Thus, the study was aimed to determine the epidemiological and clinical characteristics, exploratory analysis, and potential exposures associated with the disease.

\section{MATERIAL AND METHOD Study design}

A descriptive cross sectional study was conducted in Balochistan province, from March to April 2020.

\section{Description of the study area}

Balochistan province being highly porous borders has unique challenges. It is sandwiched between two epicenters of Corona that is Afghanistan and Iran. Despite limited available resources, the province has a sufficiently raised level of preparedness. Covid-19 emergency operational center (EOC) was the first development by the Director General Health Services (DGHS) to keep the spread at bay. Rapid Response Teams for Covid-19, frontier corps (FC) frontline personals, Medical and paramedical staff were enlisted and trained to monitor the point of entries, surveillance, contact tracing, awareness sessions among communities, and maintenance of logistics issues. Isolation and Quarantine centers were developed in various health facilities of the province and diagnostic laboratories were verified by WHO Laboratory specialists. To count down COVID-19 confirmed case figures, two diagnostic facilities were utilized by the department; a pre-existing public health laboratory in government setting at Fatima Jinnah Chest \& General hospital and a temporary Mobile Taftan laboratory. Taftan laboratory collects all the suspected samples that came from various linked border routes. By using WHO standard protocol, nasopharyngeal and oropharyngeal swab samples were taken and real time- polymerase chain reaction (RT-PCR) kits provided by the National Institute of Health $(\mathrm{NIH})$, Islamabad, were used for detection.

Data App (COVID-19 Dashboard) has been developed, to ensure the timeliness and data quality. Active surveillance and screening have been established in 08 porous entry points; Quetta airport, Turbat airport, Gwadar airport, Turbat cross border, Gwadar cross border, Panjgoor Cross border, Taftan cross border, Chaman cross border Killaabdullah. Taftan a cross border with Iran is located in district Chagai, Balochistan. Each year hundreds of pilgrims use this cross border for religious pilgrimages and returned back via same route. Data from all preset points are collected and analyzed in DGHS, Covid-19 emergency operational center.

\section{Study Population}

After a public health emergency declared by WHO, formal screening and investigation of various entry points began on January 1, 2020, supported by DGHS, Balochistan. The data on screened, suspected, and clinically diagnosed taken from electronic COVID-19 Dashboard of the health department, Government of Balochistan. All personals entered the province from eight porous border routes, predominately from Taftan cross border, are screened and investigated. All the suspected cases were entered in electronic Dashboard while their COVID-19 positive status was updated after laboratory confirmation. All the suspected cases were extracted from electronic Dashboard from March to April and are included in study. In particular, ethical approval was obtained through the Provincial health department. However, patient confidentiality and privacy were protected during the study.

\section{Data collection and Source}

A public health emergency and Class B notifiable disease required all cases to be reported instantaneously to COVID -19 emergency operational center. Each case recorded into the system by health care providers and field epidemiologists who collected information and investigate potential exposures. To avoid duplication, 
Table 1: Epidemiological characteristics of COVID-19 confirmed cases reported in Balochistan from March-April 2020

\begin{tabular}{|c|c|c|c|}
\hline Demographic parameter & No. of cases $(\%) n=1049$ & Deaths (\%) & CFR \% \\
\hline \multicolumn{4}{|l|}{ Gender } \\
\hline Male & $811(77)$ & $11(76)$ & 1.35 \\
\hline Female & $238(23)$ & $3(21)$ & 1.26 \\
\hline \multicolumn{4}{|l|}{ Province } \\
\hline Balochistan & $1013(97)$ & $14(100)$ & 1.38 \\
\hline Other & $36(3.4)$ & 0 & 0 \\
\hline \multicolumn{4}{|l|}{ Comorbid conditions } \\
\hline Cardiovascular disease & $2(0.2)$ & $2(14)$ & 100 \\
\hline ARDS/COPD & $4(0.4)$ & $3(21)$ & 75 \\
\hline Diabetes & $7(0.7)$ & $3(21)$ & 43 \\
\hline Hypertension & $11(1.05)$ & $2(14)$ & 18.1 \\
\hline Carcinoma & $2(0.2)$ & $1(07)$ & 50 \\
\hline Renal failure & $6(0.6)$ & $2(14)$ & 33.3 \\
\hline None & $1017(96)$ & $1(07)$ & 0.09 \\
\hline
\end{tabular}

all suspected cases have records in the system, also contain identification number. All data contained in COVID-19 Dashboard were extracted from the system through April 30, 2020. Neither any eligibility criterion was used nor was a predetermined sample size done. All cases from March to April 2020 were included. The results of the laboratory finding as well as data acquired through COVID-19 Dashboard was cleaned and complied on Microsoft excel sheet. Then entered in statistical software (EPI INFO) version 7.2

\section{Variables included}

Epidemiological investigation and patient characteristics were collected from COVID-19 Dashboard. Patients were categorized as if they are health workers for occupation variable. Certain exposures were determined like having travel history if they had recently lived in or visited other cities or country particularly China and Iran. Or if they had close contact with someone ill, declared positive for COVID-19. The comorbidity variable was also determined upon the epidemiological investigation of positive cases only by patient medical history. The symptoms variable was categorized based on various signs and symptoms; Fever, cough, Runny nose, headache, body ache sore throat, chills, shortness of breath. The symptom severity was not included as most cases remain asymptomatic even after getting a positive result.

For the epidemiological curve; the date of sample taken, date of diagnosis and date of onset were recorded. Cases were categorized as confirm (diagnosis based on lab finding, PCR result), clinically diagnosed (diagnosis based on clinical manifestation), suspected (diagnosis based on clinical features and exposure) and asymptomatic (based on lab finding but without any clinical feature). The date of diagnosis was used as the date of onset for asymptomatic cases.

Ethical Approval: An ethical approval was taken from Department of Health, Balochistan Pakistan.

\section{RESULTS}

A total of 1381 records were extracted from the system and were included in the analysis. Thus, all 1381 individuals were screened and $88 \%$ (1218) were suspected for COVID-19 as of April 30, 2020. Among them, overall 86\% (1049) cases were confirmed verified by lab results. Of these, $22 \%$ (227) were suspected cases, $18 \%$ (188) clinically diagnosed cases, and $37 \%$ (387) were asymptomatic cases. The characteristics of positive cases (1049) are presented in Table 1.

Among 1049 cases, a majority were 77\% (811) were male and $23 \%$ (238) were female. A majority of cases 97\% (1013) were from various regions of Balochistan province while $3.4 \%$ (36) travelled back from Iran, and were of other parts of the country. As shown in Table 1 among 1049 confirmed cases, a total of 14 deaths have occurred with an overall case fatality rate of $1.33 \%$. Patients with comorbid conditions had much higher case fatality rates for Cardiovascular disease $100 \%$, Acute respiratory disease syndrome $75 \%$ followed by Carcinoma $50 \%$. However, cases reported not any comorbid conditions had a case fatality rate of $0.09 \%$. A similar pattern was observed for the Attack rate. Age group and district wise attack rates are given in Table 2. The highest attack rate $1.90 / 10,000$ was found in age group $60-69$ years, followed by $30-39$ years with AR 1.74 per 10,000. The overall attack rate was 0.70 per 10,000 .

On March 10, 2020 COVID-19 emergency operational center confirmed the existence of first imported case of COVID-19 who came from Iran. As of April 30, 2020 a total of 1049 confirmed cases were reported from 18 districts of province. Of these, 36 cases were from other parts of country, travelled back from Iran. The Geo-temporal finding of COVID-19 in Balochistan province is shown in Figure 1.

Figure $2 A$ shows the COVID-19 epidemiological description bar chart that illustrates the disease progression among various occupations. A total of 1218 cases distinguished as $39 \%$

(477) 
asymptomatic cases , 20\% (248) confirmed cases, $15.4 \%$ (187) clinically diagnosed cases, and $25 \%$ (306) suspected cases. The highest no. of cases was found in house wives $18 \%$ (219), students $13.3 \%$ (162), and health care providers $13 \%$ (159). While among 14 deaths, 29\% (04) elderly, 21\% (03) health care providers, housewives, and shopkeepers, and 7\%(01) labour deceased. Primarily, 79\% (11) admitted in hospital with the pre-existing comorbid condition while $21 \%$ (3) died due to contact history.

A total of $61 \%(741 / 1218)$ of clinically diagnosed, confirmed and suspected cases exhibit clinical signs and symptoms while 39\% (477) remain asymptomatic. Majority of cases depict fever $57 \%$ (423), cough 26\% (192), runny nose 6.5\% (48), body ache $9 \%(69)$, headache $16 \%$ (121), sore throat $14 \%$ (102) and dyspnea $11 \%$ (78). We further classified cases as mild, severe, and critical. Mild cases 52\% (631) are those exhibit no pneumonia or minor signs, $6.4 \%$ (78) severe cases showed pneumonia or dyspnea symptoms while critical $2.6 \%$ (32) are those who have had pneumonia symptoms along with comorbid conditions.

Table 2: Age and district wise attack rates for the infected COVID-19 cases.

\begin{tabular}{|c|c|c|c|c|}
\hline Age group & cases & Percentage & Population & Attack rate/10,000 \\
\hline $0-9$ & 61 & 5.82 & $3,758,872$ & 0.16 \\
\hline $10-19$ & 114 & 10.86 & $2,878,716$ & 0.39 \\
\hline $20-29$ & 258 & 24.59 & $2,017,076$ & 1.27 \\
\hline $30-39$ & 237 & 22.59 & $1,356,650$ & 1.74 \\
\hline $40-49$ & 168 & 16.11 & 983,849 & 1.70 \\
\hline $50-59$ & 106 & 10.11 & 661,660 & 1.60 \\
\hline $60-69$ & 76 & 7.24 & 399,959 & 1.90 \\
\hline $70-79+$ & 29 & 2.76 & 2833921 & 0.10 \\
\hline \multicolumn{5}{|l|}{ Districts } \\
\hline Chagi & 9 & 0.85 & 241,498 & 0.37 \\
\hline Gwadar & 1 & 0.09 & 263,514 & 0.03 \\
\hline Harnai & 2 & 0.19 & 103,666 & 0.19 \\
\hline Jafferabad & 18 & 1.72 & 549,028 & 0.32 \\
\hline Kacchi Bolan & 1 & 0.09 & 253,275 & 0.03 \\
\hline Kharan & 3 & 0.28 & 166,854 & 0.17 \\
\hline Khuzdar & 1 & 0.09 & 857,187 & 0.01 \\
\hline Killaabdullah & 14 & 1.33 & 809,499 & 0.17 \\
\hline Loralai & 7 & 0.67 & 424,636 & 0.16 \\
\hline Mastung & 16 & 1.52 & 284,723 & 0.56 \\
\hline Musakhail & 1 & 0.09 & 178,464 & 0.05 \\
\hline Noskhi & 4 & 0.38 & 191,050 & 0.21 \\
\hline Pishin & 55 & 5.24 & 786,705 & 0.69 \\
\hline Quetta & 864 & 82.36 & $2,431,666$ & 3.55 \\
\hline Sibi & 9 & 0.85 & 144,864 & 0.62 \\
\hline Sohbatpur & 1 & 0.09 & 214,282 & 0.05 \\
\hline Zhob & 2 & 0.19 & 331,827 & 0.06 \\
\hline Ziarat & 4 & 0.38 & 171,234 & 0.23 \\
\hline Other & 36 & - & - & - \\
\hline
\end{tabular}

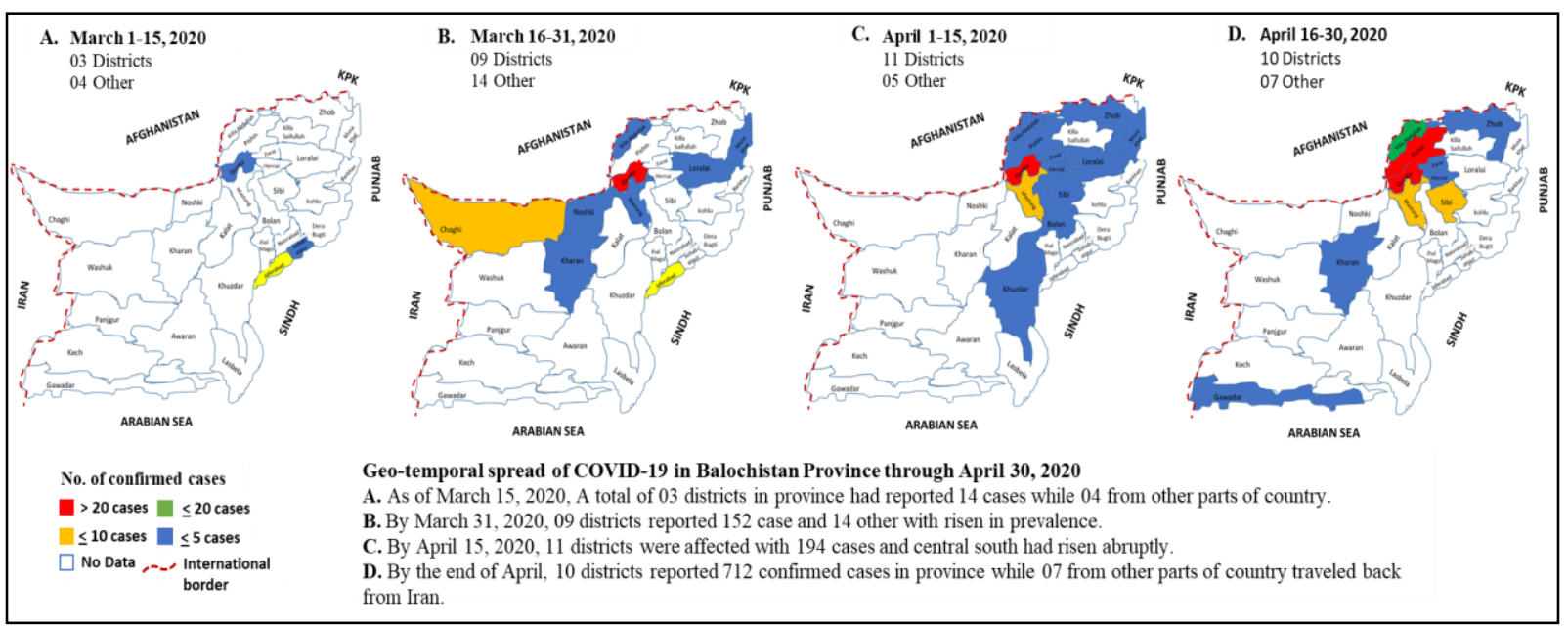

Figure 1: Geo-temporal finding of COVID-19 cases in Balochistan province from March - April, 2020. 


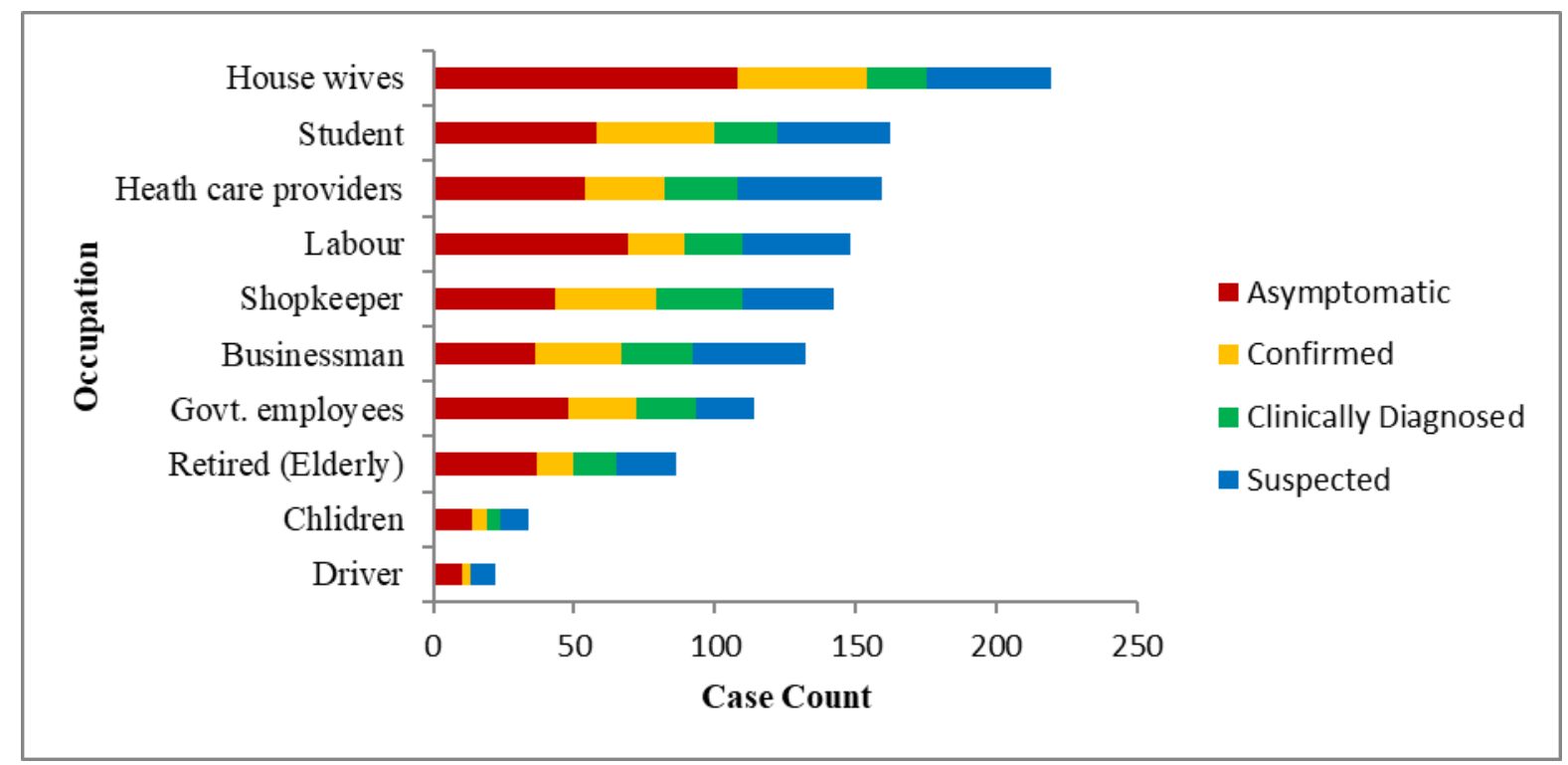

Figure 2A: Occupation wise suspected COVID-19 cases reported from Balochistan province (n=1218)

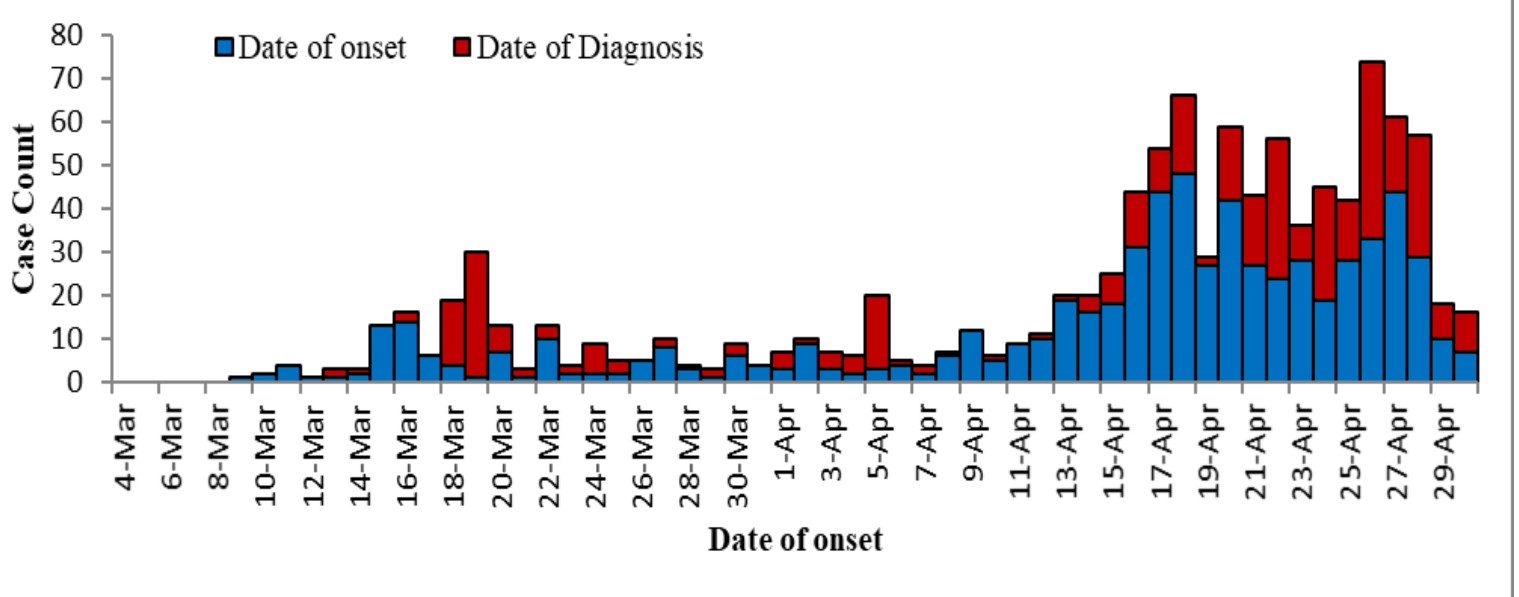

Figure 2B: Laboratory confirmed COVID-19 cases reported from Balochistan province ( $\mathrm{n}=1049)$

Figure $2 B$ shows the epidemic curve of COVID19 cases where cases were plotted by date of onset of symptoms from March 10, 2020, to April 30, 2020. During the investigation, team found most of the cases were asymptomatic that confirmed through lab findings and remained as asymptomatic. That's how the date of diagnosis was considered as the date of onset for asymptomatic cases. The first suspected case was reported on March 09, 2020 with travel history. Cases started being reported from March 10, 2020, with the first and second peak observed on March 19 and April 5, 2020, respectively. Then it began to decline in magnitude but remained prevalent and peaked again on April 24, 2020. Afterward the case count reduced gradully till Apri 30, 2020.

In connection with the different potential exposures of Corona infection, most of the patients had direct contact with COVID-19 positive persons $48 \%$ (587/1218). A total of $17 \%(205 / 1218)$ had travel history and only $6.8 \%(83 / 1218)$ of the participants reported comorbid conditions.

Contact with positive cases had higher infectivity 93\% (544/587) and admitted in hospital with comorbid conditions the lowest 39\% (32/83). Having contact with infected persons was associated with a high association of $97 \%$ (323/333) than without any contact $87 \%(221 / 254)$. Those had travel history showed the association of $86 \%(87 / 101)$ than in those who did not $58 \%$ (60/104) while those admitted in hospital with comorbid conditions showed the association of $70 \%(26 / 37)$ than in those who did not $13 \%(6 / 46)$. The detail about exposure category and their impact on disease spread is given in Table 3. 
Table 3: Exposure of various signs \& symptoms with risk factors and impact on disease spread.

\begin{tabular}{|c|c|c|c|c|c|c|c|c|c|c|c|c|c|}
\hline \multicolumn{2}{|c|}{ Exposure Category } & Fever & Cough & $\begin{array}{l}\text { Runny } \\
\text { nose }\end{array}$ & $\begin{array}{l}\text { Body } \\
\text { ache }\end{array}$ & $\begin{array}{l}\text { Head } \\
\text { ache }\end{array}$ & Chills & $\begin{array}{l}\text { Sore } \\
\text { throat }\end{array}$ & Dyspnea & Positive & Negative & $\begin{array}{l}\text { Chi } \\
\text { Square }\end{array}$ & $\begin{array}{l}P \text { - } \\
\text { value }\end{array}$ \\
\hline \multirow{2}{*}{$\begin{array}{l}\text { Contact with } \\
\text { +ve person }\end{array}$} & Yes & 143 & 98 & 10 & 20 & 7 & 1 & 19 & 35 & 323 & 10 & \multirow{2}{*}{21.17} & \multirow{2}{*}{0.000} \\
\hline & No & 134 & 52 & 9 & 12 & 21 & 1 & 8 & 17 & 221 & 33 & & \\
\hline \multirow{2}{*}{ Travel } & Yes & 45 & 14 & 7 & 9 & 20 & 1 & 0 & 5 & 87 & 14 & \multirow{2}{*}{20.44} & \multirow{2}{*}{0.000} \\
\hline & No & 61 & 6 & 3 & 12 & 15 & 0 & 5 & 2 & 60 & 44 & & \\
\hline \multirow{2}{*}{$\begin{array}{l}\text { Admitted } \\
\text { with } \\
\text { Comorbidity } \\
\end{array}$} & Yes & 21 & 5 & 0 & 3 & 1 & 0 & 1 & 6 & 26 & 11 & \multirow{2}{*}{28.34} & \multirow{2}{*}{0.000} \\
\hline & No & 19 & 11 & 1 & 2 & 5 & 1 & 2 & 5 & 6 & 40 & & \\
\hline
\end{tabular}

\section{DISCUSSION}

SARS-CoV-2 an emerging zoonosis accounts 10, 721,463 cases and 518233 deaths worldwide (Pakistan COVID-19 Health Advisory, 2020) . Modern world has offered a series of pathogens, including Influenza, MERS-CoV, SARS-CoV-1, and SARS-CoV-2, to travel and manifest anywhere (Selvey, 2015). Thus, we delineated the key finding of epidemiological and clinical characterization of the initial 1218 cases of COVID-19 found in Balochistan province within 52 days between the first reorganization of index case to the end of the study period on April 30, 2020. First index case reported on March 10, 2020 linked to Iran- the vilest virus hit country in the Middle East (Noreen, 2020). Likewise, suspected and confirmed cases from United Kingdom, United States, Saudia Arabia, Thailand, and Hong Kong have been reported in the province but not a single case was reported from the original hub of the outbreak; china.

Taftan is the inter-linked route between Pakistan and Iran that pilgrims used to cross the border. The porous border direct dozens of pilgrims from Iran back to their cities. Taftan border has limited resources, least quarantine space increases the intensity of contact with an infected person and without proper screening or testing resulted in the virus introduction in province and ultimately into the country (Badshah, 2020; Petersen HE 2020).

COVID-19 virus found to be extremely contagious spread rapidly from one district of the province to the other. A total of 18 out of 32 districts give the figure of positive cases but the highest number of cases is reported from Quetta 82\% (864) and Pishin $5.2 \%(55)$. A similar pattern of spread is obvious and found in other witnessed studies where trend is tremendously increasing (Novel, 2020). Recently published literature of COVID-19 suggested that the young population is less reported as a case than adults particularly $60+$ elderly community. Some suggested mild illness while others reported serious illness among children (Novel, 2020; Shen, 2020; Herald Med, 2020). However, in our study the most affected age group was 60 - 69 years (attack rate $1.90 / 10,000$ ) followed by $30-39$ years (AR $1.74 / 10,000)$. Besides, the highest percentage of deaths is also reported in $60-69$ years in Pakistan (Pakistan COVID-19 Health Advisory, 2020). Yet, the role of transmission in children remains unclear. So, additional information in configuration with future studies and sero-epidemiological surveys may highlight this aspect exclusively.

In the long run to rapid spread, it is unforeseen that in our finding COVID-19 has been mild for 52\% (631) of cases with a low case fatality rate of $1.33 \%$ that is substantially lower than overall country case fatality rate $2.3 \%$. Other highly hit countries reported case fatality rate of $13.6 \%$ Italy, 6.3\% Iran, 5.7\% United States of America, 3.3\% India and 2.9\% Afghanistan on April 30, 2020 (WHO COVID-19 Dashboard, 2020).

Among 14 deaths, majority have been $55-86$ years. A total of $3.1 \%$ (32) have had pre-existing comorbid conditions but $93 \%$ (13) deaths occurred in cases with high hit comorbid conditions such as cardiovascular disease, acute respiratory disease syndrome followed by Carcinoma. In particular, immunosuppressed and normal populations both are susceptible to COVID-19 infection as it spread through exposure to the virus. It has been suggested that people with poor immune function along with comorbid conditions like renal and hepatic dysfunction are more prone to get critically infected (Worldometer, 2020). The elderly wider community with comorbidities is more prone to be infected with SARS-COV-2. Precisely, people have had hypertension, coronary heart disease; diabetics, tumor and Parkinson's disease are more likely to develop severe symptoms if infected with novel coronavirus (Alhogbani, 2016; Li, 2020; Zheng, 2020). Historically, Middle East respiratory syndrome-related coronavirus is known to cause acute myocarditis, heart failure and ultimately increased the risk of death. Studies more emphasize cardiovascular disease patients' account for a large proportion of deaths from COVID-19 (Wang, 2020; Zheng, 2020).

Balochistan witnessed a spike of COVID-19 cases from April 18, 2020. The number of suspected cases increases within days but limited testing capacity hinders the true picture of epidemic. During mid-March strict travel restriction and lockdown were implemented by the government. But during this lockdown phase, the case count continuously increased favor the spread. It is unforeseen that the government unable to control 
wider community as well as failed to implement the complete ban and social distancing (Noreen, 2020). Local spread starts at end of mid-March. Within the meantime of study, the numbers of confirmed cases exceed thousands; this further spread was intensified by people inconsistent with preventive measures and social distancing. Though, the Government of Pakistan approved National Preparedness and Response Plan for COVID-19 under Global Health Security Agenda (GHSA) to combat the unprecedented outbreak of novel coronavirus (Ministry of Health services, Regulations and Coordination, 2020).

Hence, provinces particularly Balochistan province need to pledge into extensive long term activities to ensure preparedness and response protocols at each level. The major strength of our study is to extract all the cases reported through April 30, 2020. Yet, all cases were at rock-bottom diagnosed and investigated by trained staff. Nevertheless, our study did have few essential limitations. Firstly, a few records were missing for essential variables of interest like comorbid conditions, case severity, and travel-related expose. Limited testing capacity and limited resources belie the actual figures.

\section{Future directions to control the spread in Province}

Novel coronavirus drastically undermines the world's economy, health system and livelihood in just a few months; incapacitate not only the underdeveloped countries but also developed countries. In particular, our study delineated the rapid spread of novel coronavirus in the wider community. The potential risk factors are associated with disease transmission. However, uncertainty for transmission routes, identification of animal reservoir and period of infectiousness dissemble prevention pathway. To control the current outbreak, extensive measures have already been adopted by the government to reduce the person-to-person transmission of COVID-19. Yet, ample attention and efforts are required to protect the vulnerable populations. Nevertheless, the wider community is susceptible to acquire COVID-19 infection but health care providers and people who come into contact or care for COVID-19 patients, are highly vulnerable. Ensuring adequate infection and prevention control (IPC) measures are essential to implement in health care units. Test, trace and quarantine as well as coordination and technical support to the community are essential to assess the potential risk factors, discontinuous the transmission pattern and identity the hotspots to implement targeted lockdown to prevent future spread.

Public health and social measures (PHSM) such as restriction of movement, business and educational institute closer and international travel restrictions, have been implemented by countries around the world. Partial or complete reopening is a circumspect task that should be guided by risk and event-based approaches to ensure and maximize the control measures. Decontaminated reagents for cleaning hands should utilize on daily basis and should be provided by public and private services. Transboundary movements and trade routes should be screened for unlimited time frame to control the further spread of virus.

\section{Competing Interests: None.}

\section{REFERENCES}

Alhogbani, T. (2016). Acute myocarditis associated with novel Middle East respiratory syndrome coronavirus. Annals of Saudi medicine, 36(1), $78-80$

Bastola, A., Sah, R., Rodriguez-Morales, A. J., Lal, B. K., Jha, R., Ojha, H. C., \& Morita, K. (2020). The first 2019 novel coronavirus case in Nepal. The Lancet Infectious Diseases, 20(3), 279-280.

Bogoch, I. I., Watts, A., Thomas-Bachli, A., Huber, C., Kraemer, M. U., \& Khan, K. (2020). Pneumonia of unknown aetiology in Wuhan, China: potential for international spread via commercial air travel. Journal of travel medicine, 27(2), taaa008.

Bassetti, M., Vena, A., \& Giacobbe, D. R. (2020). The novel Chinese coronavirus (2019-nCoV) infections: Challenges for fighting the storm. European journal of clinical investigation, 50(3), e13209.

Badshah, S. L., Ullah, A., Badshah, S. H., \& Ahmad, I. (2020). Spread of Novel coronavirus by returning pilgrims from Iran to Pakistan. Journal of Travel Medicine, 27(3), taaa044.

Carlos, W. G., Dela Cruz, C. S., Cao, B., Pasnick, S., \& Jamil, S. (2020). COVID-19 Disease due to SARS-CoV-2 (Novel Coronavirus). American Journal of Respiratory and Critical Care Medicine, 201(4), 7-P8.

Coronavirus Outbreak. Available at: https://www.worldometers. info/coronavirus/. Accessed 23 July 2020.

Government of Pakistan (2020) COVID-19 Health Advisory Platform by Ministry of National Health Services Regulations and Coordination http://covid.gov.pk/stats/global Accessed 23 July 2020.

Government of Pakistan, Ministry of Health services, Regulations and Coordination (2020) National Action Plan for Preparedness \& Response to Corona Virus Disease (COVID19) Pakistan. https//www.nih.org.pk/wpcontent/uploads/2020/02/NAP-covid19_AL@version-3-date-12-2-2020-withannexures.pdf Accessed 23 July 2020. 
Herald Med. (2020) Medical expert group of Tongji hospital. Quick guide to the diagnosis and treatment of pneumonia for novel coronavirus infections (third edition). Accessed 23 July 2020

Huang, C., Wang, Y., Li, X., Ren, L., Zhao, J., Hu, Y., \& Cheng, Z. (2020). Clinical features of patients infected with 2019 novel coronavirus in Wuhan, China. The lancet, 395(10223), 497-506.

Lee, A. (2020). Wuhan novel coronavirus (COVID-19): why global control is challenging. Public health, 179, A1.

Li, T., Wei, C., Li, W., Hongwei, F., \& Shi, J. (2020). Beijing Union Medical College Hospital on" pneumonia of novel coronavirus infection" diagnosis and treatment proposal (V2. 0). Med J Peking Union Med Coll Hosp. http://kns.cnki.net/kcms/detail/11.5882.r.20200 130.1430.002.html. Accessed 23 July 2020.

Lu, H., Stratton, C. W., \& Tang, Y. W. (2020). Outbreak of pneumonia of unknown etiology in Wuhan, China: The mystery and the miracle. Journal of medical virology, 92(4), 401-402.

Millán-Oñate, J., Rodriguez-Morales, A. J., Camacho-Moreno, G., Mendoza-Ramírez, H., Rodríguez-Sabogal, I. A., \& Álvarez-Moreno, C. (2020). A new emerging zoonotic virus of concern: the 2019 novel Coronavirus (SARS CoV-2). Infectio, 24(3), 187-192.

Noreen, N., Siddiqui, SW., Niazi SUK., Khudaidad F, Khudaidad., NU, Khan., Dil S., Khan, MA., \& Naveed, I. (2020). COVID-19 Outbreak in Pakistan; a Situational Analysis. Journal of Emerging Diseases and Virology. 5. 10.16966/2473-1846.153.

Noreen, N., Dil, S., Niazi, S. U. K., Naveed, I., Khan, N. U., Khan, F. K., Kumar, D. (2020). COVID 19 Pandemic \& Pakistan; Limitations and Gaps. Global Biosecurity, 1(4).
Novel, C. P. E. R. E. (2020). The epidemiological characteristics of an outbreak of 2019 novel coronavirus diseases (COVID-19) in China. Zhonghua liu xing bing xue za zhi= Zhonghua liuxingbingxue zazhi, 41(2), 145-151.

Petersen HE, Baloch SM (2020) Pakistan coronavirus cam: 'No facilities, no humanity.'

Selvey, L. A., Antão, C., \& Hall, R. (2015). Evaluation of border entry screening for infectious diseases in humans. Emerging infectious diseases, 21(2), 197.

Shen, K., Yang, Y., Wang, T., Zhao, D., Jiang, Y., Jin, R., \& Shang, Y. (2020). Diagnosis, treatment, and prevention of 2019 novel coronavirus infection in children: experts' consensus statement. World journal of pediatrics 16, 223-231.

WHO Corovirus Disease Dashboard https://covid19.who.int/ Accessed 23 July 2020

Wang, D., Hu, B., Hu, C., Zhu, F., Liu, X., Zhang, J., \& Zhao, Y. (2020). Clinical characteristics of 138 hospitalized patients with 2019 novel coronavirus-infected pneumonia in Wuhan, China. Jama, 323(11), 1061-1069.

Yang, X., Yu, Y., Xu, J., Shu, H., Liu, H., Wu, Y., ... \& Wang, Y. (2020). Clinical course and outcomes of critically ill patients with SARSCoV-2 pneumonia in Wuhan, China: a singlecentered, retrospective, observational study. The Lancet Respiratory Medicine 8(5), 475481

Zheng, Y. Y., Ma, Y. T., Zhang, J. Y., \& Xie, X. (2020). COVID-19 and the cardiovascular system. Nature Reviews Cardiology, 17(5), 259-260.

Zhu, N., Zhang, D., Wang, W., Li, X., Yang, B., Song, J.,\& Niu, P. (2020). A novel coronavirus from patients with pneumonia in China, 2019. New England Journal of Medicine 282(8), 1-7 